\title{
Range prediction and e-mobility - The complexity behind a length scale
}

Rafael Abel, F. Beutenmüller, S. Stein

TWT GmbH

This manuscript is not available according to publishing restriction.

Thank you for your understanding.

(c) Springer Fachmedien Wiesbaden GmbH, ein Teil von Springer Nature 2020 